\title{
Does the national program of prevention of mother to child transmission of HIV (PMTCT) reach its target in Ouagadougou, Burkina Faso?
}

\author{
Eric. N. Some ${ }^{1}$, Nicolas Meda ${ }^{2}$
}

1. Health Research Institute (IRSS) Burkina Faso, Department of Public Health and Biology

2. CRIS/ANRS, University of Ouagadougou

\begin{abstract}
Background: In the context of universal access to prevention, treatment, care and support, each country has to ensure that $80 \%$ of women and children in need have access to PMTCT interventions.

Objective: To assess the PMTCT program achievement in Ouagadougou, the capital city of Burkina Faso.

Methods: Between August and October 2008, a cross sectional study was carried out in the five health districts of the Centre Health Region. We reviewed weekly statistics from all health care centres (HCC) to compute the coverage of PMTCT program. In 38 HCC with functional PMTCT program, we extracted data of interest from HCC registers and made direct observations of PMTCT services.

Results: The PMTCT program was implemented in 49\% of HCC (target for the national program: 70\%). Fifteen to $31 \%$ of these centers were often in shortage for PMTCT consumables. Patients' privacy was not observed in 67\% of Voluntary Counselling \& HIV Testing wards. Care providers were not qualified enough to deliver PMTCT services. Vitamin A supplementation was not implemented. None of the facilities offered the whole package of PMTCT program interventions. HCC providing HIV testing in labour or in postnatal ward were consistently lacking. Only $86 \%$ of antenatal care new attendants benefited from pre-test counselling; $2.4 \%$ of pretested women were HIV-positive and 39\% of positive mothers received antiretroviral prophylaxis.

Conclusion: Coverage and quality of PMTCT programme in the Centre Health Region in Burkina Faso are still limited. Particular support is needed for training, supervision and infrastructures upgrading.
\end{abstract}

Key words: vertical transmission, HIV infection, program, implementation.

DOI: http://dx.doi.org/10.4314/ahs.v14i4.17

\section{Introduction}

HIV infection prevalence in Africa varies from $15 \%$ to $40 \%$ among pregnant women in countries where HIV prevalence is highest and where the proportion of women of reproductive age is higher than $55 \%$ of HIV infected adults ${ }^{1}$. From 2005 to 2009, mother to child transmission (MTCT) has caused more than 500000 HIV infections among new-born ${ }^{2}$. MTCT is the most important route of HIV transmission among children. Of these infections, 90\% occur in Sub Saharan Africa (SSA). Currently, effective strategies to reduce MTCT risk in resources limited settings are available ${ }^{3-16}$. They are widespread and the global commitment towards the Prevention of MTCT (PMTCT) of HIV is significant. However, challenges to implement and

\footnotetext{
Corresponding author:

Eric Some

Health Research Institute (IRSS) Burkina Faso, Department of Public Health and Biology

10 BP 250 Ouagadougou 10

Burkina Faso

Tel: +22678849574

E-mail: eric.nsome@gmail.com
}

scale up PMTCT programs have been reported in most of the African countries, including Burkina Faso ${ }^{1,2}$. In 2006, despite efforts to extend PMTCT care, less than $10 \%$ of pregnant HIV infected women in Africa benefitted from interventions to reduce MTCT. In Eastern and Southern Africa, only 17\% of HIV infected women were detected through HIV testing and $11 \%$ received ARV based prophylaxis. In western and central Africa 3\% of infected women were tested and $1 \%$ received ARV prophylaxis ${ }^{1,2}$.

Even in settings where an effective prophylaxis was available during pregnancy and delivery, important gaps persisted during the postnatal period. A few PMTCT programs succeeded in reaching women and babies once they went back home, to provide them with continuous counseling and guidance in the mothers' feeding options for the baby as well as care and treatment ${ }^{2}$.

In Burkina Faso from 2006 to 2010, the national PMTCT program included 5 components of which the third was preventing HIV transmission from infected mothers to their offspring ${ }^{17}$. The key elements of this component included i) counselling and screening of 
HIV infection in women, ii) the use of antiretroviral servation of PMTCT units and service provision. We medicines to reduce MTCT, iii) safer or "cleaner" ob- listed also all infrastructures and materials used to stetrical practices and iv) feeding counselling for the perform PMTCT activities.

new-borns. The program planned to cover $70 \%$ of the HCC by the end of 2007 .

Twenty investigators, who were divided into 10 teams consisting of two individuals, collected the data.

Today, in the PMTCT option B+ era, it still appears rel- A four-days training with a pilot test preceded the inevant to assess the performance of the PMTCT pro- vestigation. The field investigation lasted 10 davs. We gram in the health region of the centre, in a period collected data regarding the characteristics of the HCC where HIV programs were better funded, to shed more (location, level in the health care system, type as public light on what could potentially be the implementation or private), the equipment and supply chain, the human challenges for the WHO new PTMCT guidelines. Spe- resources and working conditions, the care provided cifically, our objectives were to assess the quality and and the PMTCT cascade. We obtained the required authe achievements of the national PMTCT program thorization from the national Ethics Committee and during the first six months of 2008 as compared the regional health office. The study was conducted to the country goals and standards described in in accordance with the Helsinki declaration. We used the PMTCT program document ${ }^{17}$

\section{Method}

\section{Study plan and context}

the Epi Info 2000 software to run a univariate descriptive analysis of the data.

\section{Results}

Centres (HCC) implementing tween August and October 2008 using FHI PMTCT PMTCT, 28 were located in an urban area, 35 were priprograms assessment guidelines ${ }^{18}$. The survey included mary HCC (the three others were first reference level the five districts of the Centre Health Region in Burkina centres), 32 were public, and six were private for- not Faso. This Region consists of the city of Ouagadougou profit.

and its neighborhoods. We enumerated in a census, al

HCC that were implementing the PMTCT program at Human resources and working conditions at PMTCT the end of the first six months of 2008 .

\section{Data collection}

We first reviewed PMTCT program documents. The field data collection consisted of completing questionnaires with the PTMCT agents and direct ob-
Table 1: Protocols, equipment and commodities into VCT/ANC services in the sanitary region of the centre $(\mathbf{N}$ is varying because of missing data)

\begin{tabular}{|c|c|c|}
\hline Items $(\mathrm{N})$ & $\begin{array}{l}\text { Number } \\
\text { Avalabbility of guidelines }\end{array}$ & Percen \\
\hline $\begin{array}{l}\text { PMTCT guidelines } \\
\text { Potuntart testing and counseling }\end{array}$ & 22 & 59.4 \\
\hline 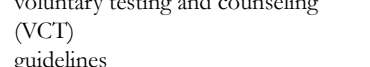 & 21 & 56.7 \\
\hline $\begin{array}{l}\text { guvddhines } \\
\text { infants feeding } \\
\text { counseling guidelines }\end{array}$ & 17 & 56.7 \\
\hline $\begin{array}{l}\text { counseling guuddines } \\
\text { IMCI guidelines } \\
\text { manangement of }\end{array}$ & $\begin{array}{l}16 \\
25\end{array}$ & $\begin{array}{l}43.2 \\
67.5\end{array}$ \\
\hline $\begin{array}{l}\text { sexually transmitted } \\
\text { infections (STIs) } \\
\text { owidelines }\end{array}$ & & \\
\hline $\begin{array}{l}\text { gumdenines } \\
\text { Postition prophylaxis } \\
\text { guidelines } \\
\text { family phanning guiddelineses }\end{array}$ & 11 & 29.7 \\
\hline $\begin{array}{l}\text { counseling for HIV- positive women } \\
\text { corlons }\end{array}$ & $\begin{array}{l}\text { elines } 08 \\
\text { PMTCT }\end{array}$ & 21.6 \\
\hline $\begin{array}{l}\text { VCT } \\
\text { Infant feeding }\end{array}$ & $\begin{array}{l}\text { PMTCT Tervices } \\
28\end{array}$ & 75.7 \\
\hline $\begin{array}{l}\text { counseling } \\
\text { Group education }\end{array}$ & 37 & 100 \\
\hline $\begin{array}{l}\text { Groun pre test } \\
\text { counseling }\end{array}$ & 17 & 45.9 \\
\hline $\begin{array}{l}\text { Group post-test counseling } \\
\text { Individual pre-test }\end{array}$ & 11 & 29.7 \\
\hline $\begin{array}{l}\text { counseling } \\
\text { Individual post test }\end{array}$ & 31 & 83.8 \\
\hline $\begin{array}{l}\text { counseling } \\
\text { Could pre-test }\end{array}$ & 31 & 8.88 \\
\hline $\begin{array}{l}\text { Couppe pret-est } \\
\text { counseling }\end{array}$ & & 51.3 \\
\hline $\begin{array}{l}\text { Couple post test } \\
\text { counseling }\end{array}$ & 15 & 40.5 \\
\hline $\begin{array}{l}\text { HIV diaggostic } \\
\text { counseling (without testing) }\end{array}$ & 13 & 35.1 \\
\hline $\begin{array}{l}\text { Follow up counseling gum } \\
\text { Genenal nutritional }\end{array}$ & $\begin{array}{l}23 \\
28\end{array}$ & $\begin{array}{l}62.2 \\
75.7\end{array}$ \\
\hline $\begin{array}{l}\text { counseling } \\
\text { Partner family counseling }\end{array}$ & & \\
\hline $\begin{array}{l}\text { Outreach/home visit } \\
\text { Management of troubles related to }\end{array}$ & $\begin{array}{l}14 \\
16\end{array}$ & $\begin{array}{l}3.8 \\
4.78\end{array}$ \\
\hline $\begin{array}{l}\text { breastfeeding } \\
\text { ARV Prophlaxis }\end{array}$ & & \\
\hline $\begin{array}{l}\text { Akv rotopyyaxis } \\
\text { Infant formula }\end{array}$ & 15 & $\begin{array}{l}70.3 \\
40.5\end{array}$ \\
\hline $\begin{array}{l}\text { PCR for infants } \\
\text { Safe obstetric }\end{array}$ & $\begin{array}{l}07 \\
20\end{array}$ & $\begin{array}{l}18.9 \\
54\end{array}$ \\
\hline $\begin{array}{l}\text { practices } \\
\text { Elective C-section }\end{array}$ & & \\
\hline $\begin{array}{l}\text { Elective C-section } \\
\text { Sink (37) }\end{array}$ & $\begin{array}{l}04 \\
\text { Commodities }\end{array}$ & 10.8 \\
\hline $\begin{array}{l}\text { sink (37) } \\
\text { Yes } \\
\text { No }\end{array}$ & & 78.3 \\
\hline $\begin{array}{l}\text { No } \\
\text { Clean/Drinking water (32) }\end{array}$ & 8 & 21.6 \\
\hline $\begin{array}{l}\text { Yes } \\
\text { No }\end{array}$ & ${ }_{3}^{29}$ & $\begin{array}{l}78.3 \\
8.1\end{array}$ \\
\hline $\begin{array}{l}\text { Soap (31) } \\
\text { Yes } \\
\text { No }\end{array}$ & 29 & 78.3 \\
\hline $\begin{array}{l}\text { Clean towel (31) } \\
\text { Yoc }\end{array}$ & & \\
\hline $\begin{array}{l}\text { YYes } \\
\text { No }\end{array}$ & $\begin{array}{l}14 \\
17\end{array}$ & $\begin{array}{l}37.8 \\
46\end{array}$ \\
\hline $\begin{array}{l}\text { Standard examination table (37) } \\
\text { Yes }\end{array}$ & 37 & 100 \\
\hline $\begin{array}{l}\text { No } \\
\text { Waste bin (37) }\end{array}$ & 0 & 0 \\
\hline $\begin{array}{l}\text { YYes } \\
\text { No }\end{array}$ & ${ }^{37}$ & 100 \\
\hline $\begin{array}{l}\text { Register regularly filled during the } \\
7 \text { days (35) }\end{array}$ & & \\
\hline $\begin{array}{l}\text { Yes } \\
\text { No }\end{array}$ & 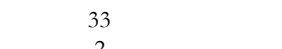 & 89.1 \\
\hline 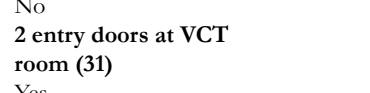 & 2 & 5.4 \\
\hline $\begin{array}{l}\text { Yes } \\
\text { No } \\
\text { At exit, can PMTCT client me } \\
\text { yes }\end{array}$ & $\begin{array}{c}8 \\
23 \\
=n t ? \\
230\end{array}$ & $\begin{array}{ll}2.0 \\
62.1\end{array}$ \\
\hline Yes & ${ }_{5}^{25}$ & 13.5 \\
\hline
\end{tabular}


staffs $(43.2 \%$ of cases), by MCH staffs trained in PMTCT in general $(40.5 \%)$ or by counselors dedicatit existed) was actually the same as the national ed to PMTCT (16.2\%). This counseling was provided it existed) was actually the same as the national ed to PMTCT $(16.2 \%)$. This counseling was provided
PMTCT program guidelines ${ }^{18}$. Among the investigated only to HIV positive pregnant women at 8 HCC. Nine HCC, 28 stated that they knew the existence of PMTCT HCC used a check list during the counseling session. All national guidelines. The others (3) did not know about centers that declared using a check list presented a or denied the existence of such document. In many copy of the document. There were two main feeding PMTCT units, different (from the national one) pro- options available for children born to HIV positive tocols were implemented and it was impossible to mothers: exclusive breastfeeding and early cessaknow their source. Of 37 interviewed HCC, four tion in all the centres and infant formula in $87 \%$ of offered elective C-section as PMTCT optional care. them. In 67.7\% of HCC, mothers preferred exclusive Forty per cent of HCC had infant formula and breastfeeding. Nutritional counseling was offered to $54 \%$ implemented safe obstetric practices. Eighteen all women at 25 HCC and only to HIV positive ANC/PMTCT units of 37 did not provide infant women at 3 HCC. When nutritional counseling was feeding counseling. Seventeen HCC had written guide- not provided, women were referred to a nutritionlines on feeding counseling; Eight HCC presented a al counselor. This reference was a routine practice copy of the guidelines document. Infant feeding coun- for 4 HCC. Group education was provided in all the seling was mostly provided by specifically trained MCH centers to women attending ANC (figure1).

\section{Figure 1 : Number of group counseling per day per HCC}

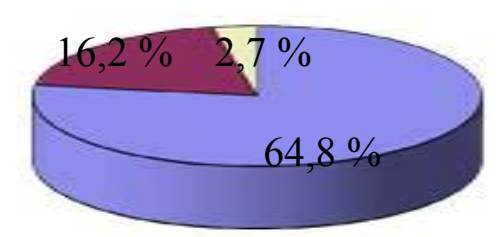

Twenty four of 32 PMTCT centres had a 25 sites investigated. Visual privacy (an external perspecific Voluntary Counseling and Testing (VCT) son could not see the people in a counselling session) units dedicated to PMTCT program. VCT sessions was observed at 21 of 29 HCC.

were provided to every woman attending ANC at

28 centres and only to women attending first ANC at VCT sessions were conducted by ANC/MCH staff at three centres. Three centers had no VCT units. VCT 25 HCC, trained counselors at 13 HCC. HIV testing was provided as a routine care at 29 centres. Pre and was performed at ANC/MCH for $19 \mathrm{HCC}$ of 33, at post test counseling sessions took place at ANC/ a dedicated VCT unit for seven centers. Six HCC did MCH unit for 14 HCC; at a PMTCT-specific VCT unit, the first testing on site and the confirmatory test at anfor 13 HCC and at another building different from the other laboratory. Rapid tests were used for women atPMTCT and ANC/MCH one, for 2 HCC tending PMTCT care everywhere. The national testing protocol was correctly implemented in 27 HCC. Four At VCT/PMTCT units, among 37 HCC, six did not HCC did not use it consistently. The reasons were that, possess a room dedicated to VCT sessions; 21 HCC either they had no knowledge of the protocol or had one room and 10 of them 2 rooms. There was au- there was a reagents shortage. Twenty two HCC ditory privacy (an external person could not hear the used protocols and guidelines to implement VCT counselling conversation) at $20 \mathrm{HCC}$ for a total of and the other 10 did not. Eight HCC showed a copy of the protocol. Blood samples for testing purpose and a waste bin as shown in table 1. Of 37 units, 29 had

were taken onsite (VCT unit) for 21 HCC and in the a sink, drinking water and soap. Fourteen HCC had a day at $32 \mathrm{HCC}$ of 33 clean towel; Eight of them had two doors at the VCT room. At the exit, $67.5 \%$ of PMTCT customers could meet another client.

Every ANC unit was set up in a standard room (with concrete walls, ceiling and floor). They all had a stand- HIV testing items (rapid test kits, lancets and gloves) ard examination table, a visit registry (regularly com- were more available than other consumables. Persispleted during the last 7 days in $89 \%$ of the units), tently, at least $19 \%$ of HCC were often in shortage of VCT and PMTCT products and consumables (Table 2).

Table 2: frequency of shortage for PMTCT products and consumables $(\mathrm{N}=26)$

\begin{tabular}{clll} 
Table 2: frequency of shortage for PMTCT products and consumables $(\mathbf{N}=26)$ & & \\
\hline $\begin{array}{c}\text { Produc } \\
\mathrm{t} / \\
\text { Consumab } \\
\text { le }\end{array}$ & $\begin{array}{l}\text { Never/ } \\
\text { scarcely } \\
*(\%)\end{array}$ & $\begin{array}{l}\text { Sometime } \\
* *(\%)\end{array}$ & $\begin{array}{l}\text { Often* } \\
* *(\%)\end{array}$ \\
\hline IEC & 18 & & 04 \\
Condom & $(69.23$ & 04 & $(15.38)$ \\
& 18 & 03 & 05 \\
AR & $(69.23$ & & $(19.23)$ \\
prophylax & 17 & 03 & 06 \\
Lancets & $(65.38$ & & $(23.08)$ \\
prick & 14 & 05 & 06 \\
HIV rapid & $(53.85$ & & $(23.08)$ \\
kits & 13 & 07 & $06(23)$ \\
Infant & $(50.00$ & & \\
& 12 & 06 & $(30.77)$ \\
\hline
\end{tabular}

* One shortage one day per month

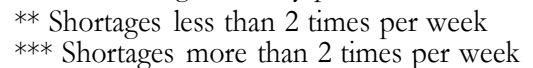

\section{Supplies and equipment at HCC}

At the ANC units, two health care centers (HCC) lacked both weighing scales and measurement ribbons (Table
3). Four of them had no tool to measure the height, and seven had no blood pressure device. (Table 3) 
Table 3: Availability of the ANC/PMTCT care products into the health care centres Items $(\mathrm{N})$

)

\section{Weighing scales}

measurement rubbon

Height measurement tool

Blood pressure device

disposable needles

and syringes

Gloves

Sharp box

Running water

Hands washing items

Iron tablets

Folic acid tablets

Multi vitamins tablets

Vitamin A supplement

tablets

Mebendazole tablets

Malaria prophylaxis

tablets

Tetanus toxoid vaccine

Gloves

HIV rapid tests kits

Lancets for rapid

testing

Sharp box

Disposable syringes

and needles

Infant formula

IEC material

ARV prophylaxis

Hand washing items

(soap or desinfectants)

ARV Sirup

Condoms

$\begin{array}{cc}\text { Number } & \text { Percentag } \\ \text { ANC units } & \\ 35 & 94.5 \\ 35 & 94.5 \\ 33 & 89.1 \\ 30 & 81 \\ 23 & 62.1 \\ & \\ 24 & 64.8 \\ 25 & 67.5 \\ 20 & 54 \\ 22 & 59.4 \\ 32 & 86.4 \\ & \\ 06 & 16.2 \\ 08 & 21.6 \\ 11 & 29.7 \\ 25 & \\ 25 & 67.5 \\ 28 & 67.5 \\ 23 & 75.67 \\ & 62.16 \\ 23 & 62.16 \\ 27 & 72.97 \\ 27 & 72.97 \\ 19 & 51.35 \\ 21 & 56.76 \\ 20 & 54.05 \\ & \\ 25 & 67.57 \\ 20 & 40.54 \\ & 54.05 \\ \text { VCT } & \\ & \\ & \end{array}$

\section{PMTCT cascade} New ANC visits were $45.3 \%$ of expected pregnan- an HIV prevalence of $385(2.4 \%)$. ARV prophylaxis cies and $39.1 \%$ of expecting women benefited from was administered to $39 \%$ of $\mathrm{HIV}$ positive women. BaPMTCT cares. Of the ANC new attendants, $86.2 \%$ got bies tested for HIV infection represented $1 \%$ of babies a pretest counselling of HIV.
Figure 2: Accrued PMTCT cascade data in the Centre Health Region

PMTCT cascade at the region level

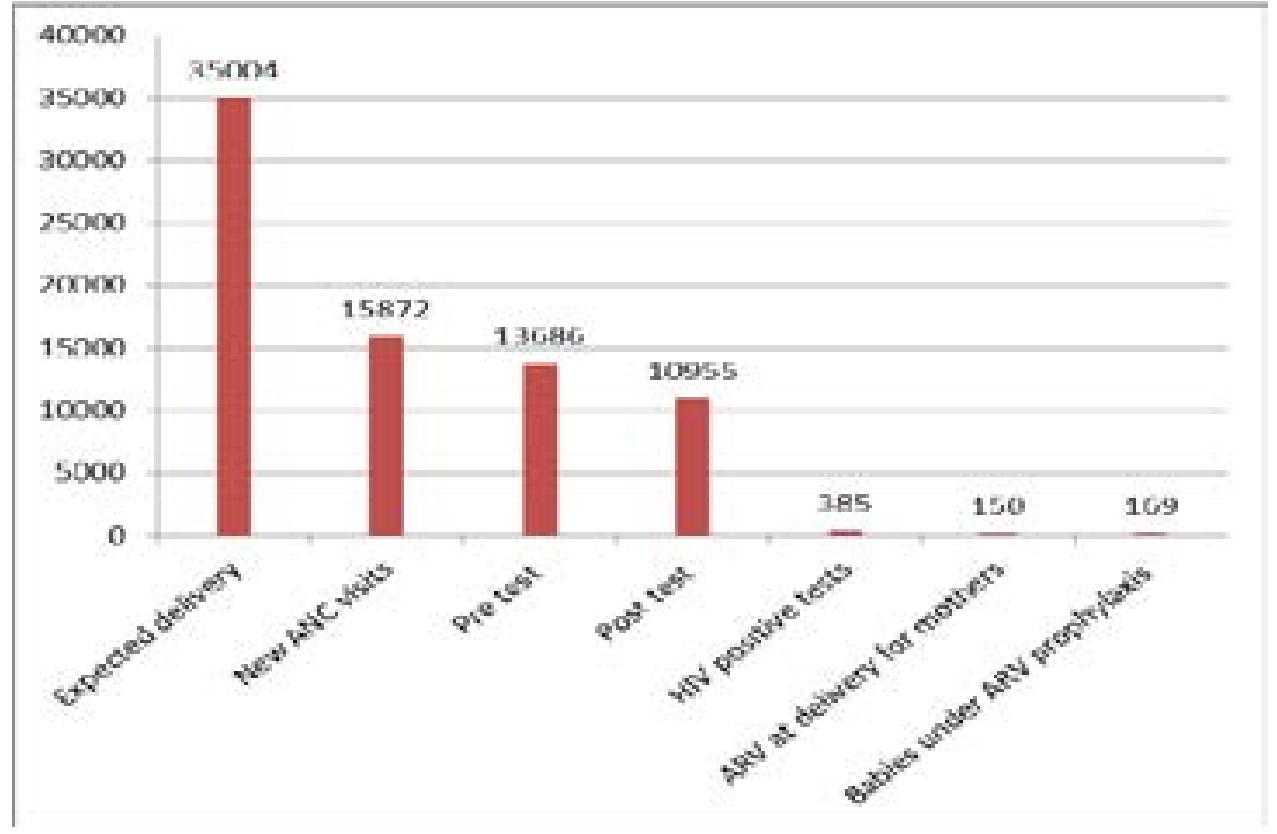

Discussion

Health Region is facing many challenges at each step of During our investigation, all the districts in the study the service chain, this finding may not be original per area were implementing PMTCT according to the se. Though, it assessed the magnitude of the difficulties 2006-2010 program's objectives ${ }^{17,19}$. However, 49\% of in PMTCT program in Burkina Faso and shed light on HCC were actually PMTCT units instead of $70 \%$ as the weaknesses of the program to be considered for planned by the program for that period. In the 2013 the implementation of the newly option B+ guidelines. national assessment of PMTCT program, $98 \%$ of HCC

were covered. The options A and B were still implemented as prophylaxis protocol.

\section{PMTCT challenges}

As compared to the rest of the world ${ }^{20}$, PMTCT cenOur results showed that PMTCT units faced many tres in the investigated sites were mainly public shortages of reagents and consumables. None of More involvement of private sector and community the HCC offered the whole package of PMTCT groups could energize the national PMTCT program. care. Mainly none of them offered testing in labor or The HIV private for-not-profit and community orpostnatal ward when a woman had not been tested ganizations could operate as HIV counseling specialists during the prenatal period. At every stage of the and outreach field actors to dramatically improve the PMTCT cascade, the loss to follow up was important. monitoring of PMTCT customers along the different Considering these results, the effectiveness and suc- cascades steps. In doing that, it would reduce the cess of the national PMTCT program in Burkina loss to follow up and ensure better quality of care. The Faso was questionable.

\section{Findings and limits} loss to follow up and ensure better quality of care. The
medical part of the program would remain assigned to qualified staff. Home-based intervention could be a great opportunity to monitor and manage effec-

We made a census of the study population (health care tive nutritional cares for mother-infant pair. That would centres implementing PMTCT program). But we used contribute to reduce the MTCT rate.

pooled data from the different HCC we investigated.

That made it impossible for us to carry in-depth analy- Infrastructures at PMTCT units are an important consis looking for associated factors. Although, this study cern. However, dedicated wards could be sources of discovered that the PMTCT program in the Centre stigma. Merging PMTCT units with the other rou- 
tine health care units would be possible if VCT session was held during the ANC visit by the same HCW. ANC wards must then be arranged accordingly. The inconvenience would be the uneven distribution of tasks; the qualified staff for ANC would also have to provide VCT sessions while less qualified personnel are not busy. The waiting delay would become longer and that could raise the number of loss to follow up. The participation of community groups and associations would become more difficult.

At national level, elective C-section is not mandatory for HIV infected pregnant women. The country is not able to provide this kind of care to every woman sustainably. However, in the study area, where technical and geographic accessibility conditions are met, presenting the different options available for a safe delivery in order to provide thorough information to HIV infected women is an ethical requirement.

Mothers, who could afford, would then opt for C-section to reduce the MTCT risk. In the same way, women who have not been tested during pregnancy must be offered the opportunity at the labor or postnatal ward. WHO recommends this practice, when it is feasible ${ }^{21}$ According to the Ghent Group ${ }^{22}$ VCT units inside $\mathrm{MCH}$ and health care centres need well trained and experienced staff, able to provide the women with all the detailed methods to reduce the HIV transmission risks. There was an average of one physician per district involved in the PMTCT program In this specific setting, such physicians' involvement is great. Did these physicians actually operate? An actual involvement of one physician per district into PMTCT program implementation should solve most of the concerns notified as shortages when it is a question of procurement or as misuse or non-consistent use of ARV prophylaxis protocol. Some studies carried out in Tanzania and Malawi reported that respectively one fourth and one hal of HIV positive women did not receive the single dose of Nevirapine and two third of babies at risk of infection were not administered the Nevirapine prophylaxis within the 72 hours after birth, although, the drugs were available. There is a gap between the number of prenatal and postnatal care attendants. actually work in the program because of lack of motivation, assignment at a position where people cannot implement PMTCT care or refusal to implement
A large part of the people trained in PMTCT did not

PMTCT care. The more the professional category PMTCT care or can be available, the less it has been trained. In Cameroon, 50\% of trained people did not contribute to the therapeutic education bia, involvement of lay counselors have been stressed in the national guidelines as a crucial point to be taken into account, in order to ensure counseling provision, monitoring and follow up of faltering customers as well as community sensitization on the importance of the HIV test in a sustainable way ${ }^{24}$.

\section{Lost to follow up in the PMTCT cascade}

The lost to follow up could be due to an actual implementation of the "opt in" strategy instead of the "opt out" one. One of the inconveniences notified about this method is the increase in workload and an important number of lost women, especially between ANC visit and VCT session. While the "opt out" strategy allows a high rate of VCT intake (more than $95 \%$ ), studies report a low rate of tested women with "opt in" strategy ${ }^{25,26}$. To improve the PMTCT cascade and the accuracy of the data, VCT units must be more available. That includes availability of buildings, PMTCT items, staff and the actual implementation of the "opt out" strategy to ensure more coverage ${ }^{22,26}$

\section{Progress in PMTCT since our surve}

In the 2013 PMTCT annual report, $88.4 \%$ of the Health Centre Region ANC new attendants were pre tested for HIV infection and $98.2 \%$ of the HCC were actually implementing PMTCT program. Among these women, $2.1 \%$ were tested positive for HIV. The follow up after delivery has also improved with $46 \%$ of the kids born to HIV infected mothers being tested by PCR at six months. ${ }^{27}$ This report highlighted the importance of NGOs and community involvement in PMTCT program. In 2013, the so called "stepping stone" or community PMTCT was started.

\section{Conclusion}

Forty nine per cent of the HCC were implementing PMTCT program, instead of $70 \%$ as per the national program goal. In general in the study region, the contents of PMTCT guidelines were not known and understood by HCW. As a result, there were important loss to follow up at different steps of PMTCT cascade. $\mathrm{MCH}$ centres did not exist. Only half of expected pregnant women attended ANC first visit. program that was the goal of their training ${ }^{23}$. In ZamMoreover an effective plan to mobilize women toward
PMTCT units were not able to provide HIV counseling 2. Kak L, Chitsike I, Luo C, Rollins N. Programmes de and testing for every pregnant woman who asked for it. They could not provide prophylaxis drugs to each mother-child pair that needed it. While nation PMTCT guidelines indicate infected mothers as the priority for treatment, HAART as PMTCT option for immuno-deficient women was crucially unavailable.

National PMTCT program should develop more leadership and synergistic partnership to build suitable infrastructures, to make sure that PMTCT supplies are consistently and sustainably available, and to motivate PMTCT field workers. It needs also to push stakeholders at the peripheral level, to take ownership of the program. It should also develop an effective supervision plan for PMTCT operators.

Since our study, improvements have been made in the program. However, worries are being raised by the discussion about the implementation and scaling up of the newly $\mathrm{B}+$ strategy that has been found the most costeffective option elsewhere ${ }^{28}$. In a context of a developing setting with very scarce resources one hand and an efficacious and cheaper A and B options (if sufficient coverage can be assured) in the other hand, is it worth engaging in unaffordable $\mathrm{B}+$ strategy with potential compliance issues?

\section{Authors'Contributions:}

Conceived and designed the study: ES, NM; implemented the study: ES; analyzed the data: ES; wrote the paper: ES, NM

\section{Acknowledgement}

The authors wish to thank the director of the health region of the Center (Ouagadougou), all the head physicians of the five health districts of the Center, the national PMTCT program, PAMAC coordinator, Fondation de France.

A special thanks to Nancy Birungi who kindly accepted to review and edit this document into better English language.

Funding: This project was funded by Fondation de France.

Competing interests: None declared

\section{References} infants. Can't we do both? GMHC treatment issues march Trials 2009 ; 30(1): 24-33.

2009.

prévention de la transmission mère-à-enfant du VIH/SIDA.www.savethechildren.org/publications/ technical-resources/saving-newborn-lives/snl-publications/oan-french/section-III-7-r2c.pdf [téléchargé le 6juin 2009]

3.Kuhn L, Aldrovandi GM, Sinkala $M$ et Al for the Zambia Exclusive Breastfeeding Study (ZEBS).

Differential Effects of Early Weaning for HIV-Free Survival of Children Born to HIV-Infected Mothers (6):e6059.

Moorthy A, Gupta A, Bhosale $\mathrm{R}$ et Al for the India SWEN Study Team. Nevirapine Resistance and Breast-Milk HIV Transmission: Effects of Single and Extended-Dose Nevirapine Prophylaxis in Subtype C HIV-Infected Infants. PLoS ONE 2009;4(1):e4096.

5. McIntyre JA, Hopley M, Moodley D et al. Efficacy of Short- Course AZT Plus 3TC to Reduce Nevirapine Resistance in the Prevention of Motherto-Child HIV Transmission: A Randomized Clinical Trial. PLoS Medicine 2009;6(10):e1000172.

6. Charurat M, Datong P, Matawal B, Ajene A, Blattner W, Abimiku A Timing and Determinants of

Mother-to-Child Transmission of HIV in Nigeria. Int Gynaecol Obstet 2009; 106(1):8-13.

7. Mmiro IA, Aizire J, Mwatha AK et al. Predictors of Early and Late Mother-to-Child Transmission of HIV in a Breastfeeding Population. I Acquir Immune Defic Syndr 2009; 52(1): 32-39.

8. Shapiro RL, Smeaton L, Lockman S et al. Risk Factors for Early and Late Transmission of HIV via Breast- Feeding among Infants Born to HIV-Infected Women in a Randomized Clinical Trial in Botswana. Infect Dis 2009; 199(3): 414-418.

. Chung MH, Kiarie JN, Richardson BA et al. Highly Active Antiretroviral Therapy (HAART) versus Zidovudine/Nevirapine Effects on Early Breast Milk HIV1 RNA: A Phase II Randomized Clinical Trial. Antivir Ther 2008; 13(6): 799-807.

10. Walter J, Ghosh MK, Kuhn L et al. High Concentrations of Interleukin 15 in Breast Milk Are Associated with Protection against Postnatal HIV Transmission. J Infect Dis 2009; 200(10):1498-1502.

11. Van der Horst $C$, Chasela C, Ahmed $Y$ et al for the BAN Study team. Modifications of a large HIV prevention clinical trial to fit changing realities: A case study of the Breastfeeding, Antiretroviral, and Nutri- 
12. Lehman DA, Chung MH, Mabuka JM et al. Lower Risk of Resistance After Short-Course HAART Compared With Zidovudine/Single-Dose Nevirapine Used for Prevention of HIV-1Mother-to-Child Transmission. J Acquir Immune Defic Syndr 2009; 51(5): 522- 529 .

13. Bland RM, Coovadia HM, Coutsoudis A, Rollins NC, Newell ML. Cohort Profile: Mamanengane or the Africa Centre Vertical Transmission Study. Int J Epidemiol 2010;39:351-360.

14. Fox MP, Brooks DR, Kuhn L et al. Role of breastfeeding cessation in mediating the relationship between maternal HIV disease stage and increased child mortality among HIV-exposed uninfected children. Int J Epidemiol 2009;38:569-576.

15. Thorne C, Semenenko I, Pilipenko T, Malyuta R, the Ukraine European Collaborative Study Group. Progress in prevention of mother-to-child transmission of HIV infection in Ukraine: results from a birth cohort study. BMC Infectious Diseases 2009; 9:40.

16. Msamanga GI, Taha TE, Young AM et al. Placental Malaria and Mother-to-Child Transmission of Human Immunodeficiency Virus-1. Am. J. Trop. Med. Hyg 2009; 80(4): 508-515.

17. Ministère de la santé, Directives nationales pour la mise en oeuvre du programme national de prévention de la transmission mère enfant du VIH 2006-2010. Ouagadougou: 2006

18. FHI, Baseline assessment tools for preventing mother-to-child transmission (PMTCT) of HIV.Arlington:1985.

19. Ministère de la santé, Programme national de prévention de la transmission mère enfant du VIH 2006- 2010 Ouagadougou : 2006.

20. National Department of Health. Policy and guidelines for the implementation of the PMTCT programme. South Africa: 2008.

21. OMS. Médicaments antirétroviraux pour traiter la femme enceinte et prévenir l'infection à VIH chez l'enfant: vers un accès universel. Recommandations pour une approche de santé publique. Suisse : 2006.

22. Dabis F, Newell ML, Fransen L et Al. for the Ghent international working group. Prevention of mother-to-child transmission of HIV indeveloping countries: recommendations for practice. HealthmPolicy plan. Oxford 2000; 15(1): 34-42.

23. Nlend AN, Nkoue N, Lyeb AS, Penda I. Mise en oeuvre d'un programme d'éducation thérapeutique en PTME et pédiatrie au Cameroun Développement et Santé 2007; 187.

24. Ministry of health, Zambia. National protocol guidelines:integrated prevention of mother-to-child transmission of HIV/AIDS.

25. Kizito D, Woodburn PW, Kesande B et al. Uptake of HIV and syphilis testing of pregnant women and their male partners in a programme for prevention of mother-to-child HIV transmission in Uganda. Tropical Medicine and International Health. 2008; 13 (5): 680-682.

26. SADC regional PMTCT technical meeting report. Gaborone: 2004.

27. Direction de la santé et de la famille Burkina Faso: programme national de prévention de la tranmission mère-enfant du VIH ; Rapport annuel 2013. Ouagadougou :2014.

28. Fasawe O, Avila C, Shaffer N, Schouten E, Chimbwandira F, et al. (2013) Cost Effectiveness Analysis of Option B+ for HIV Prevention and Treatment of Mothers and Children in Malawi. PLoS ONE. 2013; 8(3): e57778. 